\title{
Supplementary Information for: Revealing the former bed of Thwaites Glacier using sea-floor bathymetry
}

Kelly A. Hogan ${ }^{1}$, Robert D. Larter ${ }^{1}$, Alastair G. C. Graham ${ }^{2}$, Robert Arthern ${ }^{1}$, James D. Kirkham ${ }^{1,3}$, Rebecca Totten Minzoni ${ }^{4}$, Tom A. Jordan ${ }^{1}$, Rachel Clark ${ }^{5}$, Victoria Fitzgerald ${ }^{4}$, John B. Anderson ${ }^{6}$, 5 Claus-Dieter Hillenbrand ${ }^{1}$, Frank Nitsche ${ }^{7}$, Lauren Simkins ${ }^{8}$, James A. Smith ${ }^{1}$, Karsten Gohl ${ }^{9}$, Jan Erik Arndt $^{9}$, Jongkuk Hong ${ }^{10}$, Julia Wellner ${ }^{5}$

${ }^{1}$ British Antarctic Survey, Natural Environment Research Council, High Cross, Madingley Road, Cambridge, CB3 OET, UK

${ }^{2}$ College of Marine Science, University of South Florida, Saint Petersburg, FL 33701, USA

${ }^{3}$ Scott Polar Research Institute, University of Cambridge, Lensfield Road, Cambridge, CB2 1ER, UK

$10{ }^{4}$ Department of Geological Sciences, University of Alabama, Tuscaloosa, AL 35487, USA

${ }^{5}$ Department of Earth and Atmospheric Sciences, University of Houston, Houston, TX 77204, USA

${ }^{6}$ Department of Earth Science, Rice University, Houston, TX 77005, USA

${ }^{7}$ Lamont-Doherty Earth Observatory, Columbia University, Palisades, New York, USA

${ }^{8}$ Department of Environmental Sciences, University of Virginia, Charlottesville, VA 22904, USA

$15{ }^{9}$ Alfred Wegener Institute for Polar and Marine Research, Postfach 120161, D-27515, D-27515 Bremerhaven, Germany

${ }^{10}$ Korea Polar Research Institute (KOPRI), Incheon 21990, Republic of Korea

Correspondence to: Kelly A. Hogan (kelgan@bas.ac.uk) 

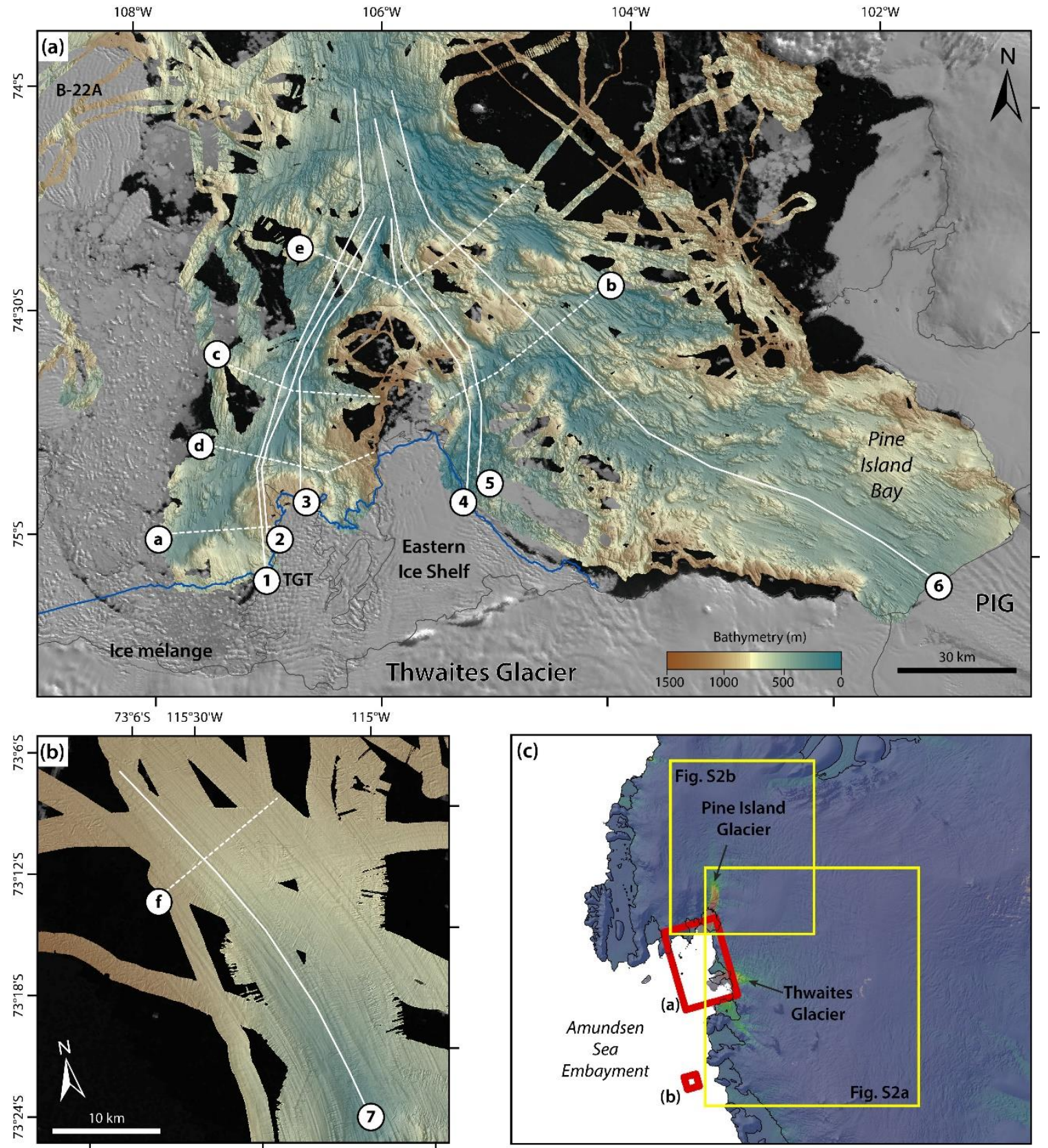

20 Supplementary Figure S1: Location maps for bed profiles used in roughness and drag contribution analyses (see Sections 2.2 and 4 in the main text). (a) Palaeo-glacier bed profiles from MBES data offshore Pine Island and Thwaites glaciers. Along-flow profiles are labelled (1)-(6); across-flow profiles are labelled (a)-(e). (b) Palaeo-glacier bed profiles for a "smooth" bed characterised by mega-scale glacial lineations (MSGL) in the mid-shelf section of Dotson-Getz Trough; along-flow profile is labelled (7), across-flow profile is labelled (f). (c) Location map of the Amundsen Sea Embayment and the Amundsen Sea sector of the West Antarctic Ice Sheet showing the locations of Supplementary Figures S1a, b (red outlines) and S2a, b (yellow outlines). 

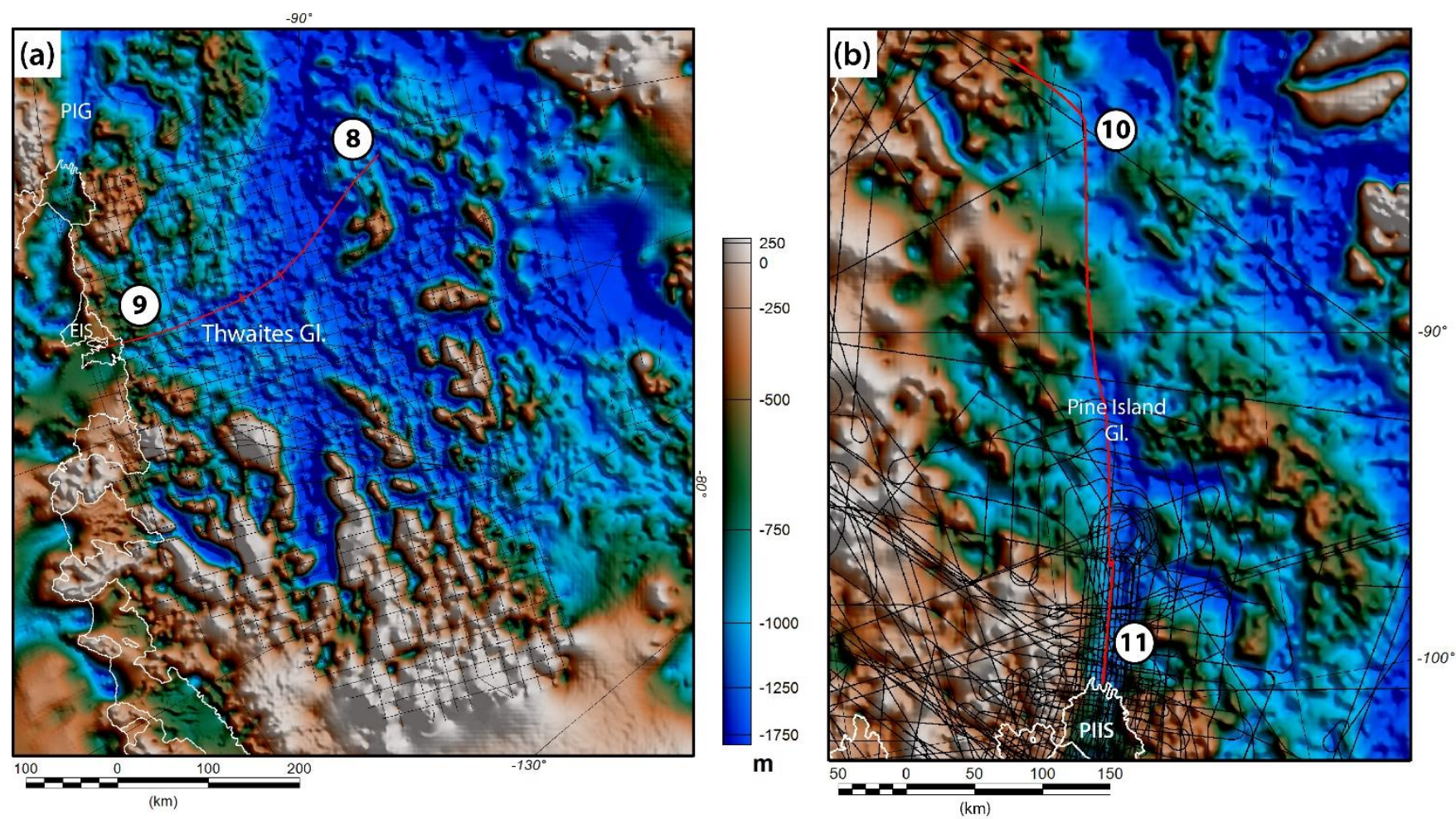

Supplementary Figure S2: Location maps for airborne radar (onshore) bed profiles used in roughness and drag contribution analyses. (a) AGASEA line used for modern Thwaites Glacier bed profiles; the tick marks denote the ends of the two profiles shown in Fig. S4f and S4g; note the overlap between the profiles. PIG is Pine Island Glacier; EIS is the Eastern Ice Shelf of Thwaites Glacier. (b) OIB profile for modern Pine Island Glacier bed profiles. PIIS is Pine Island Ice Shelf. 
(a) Thwaites area troughs
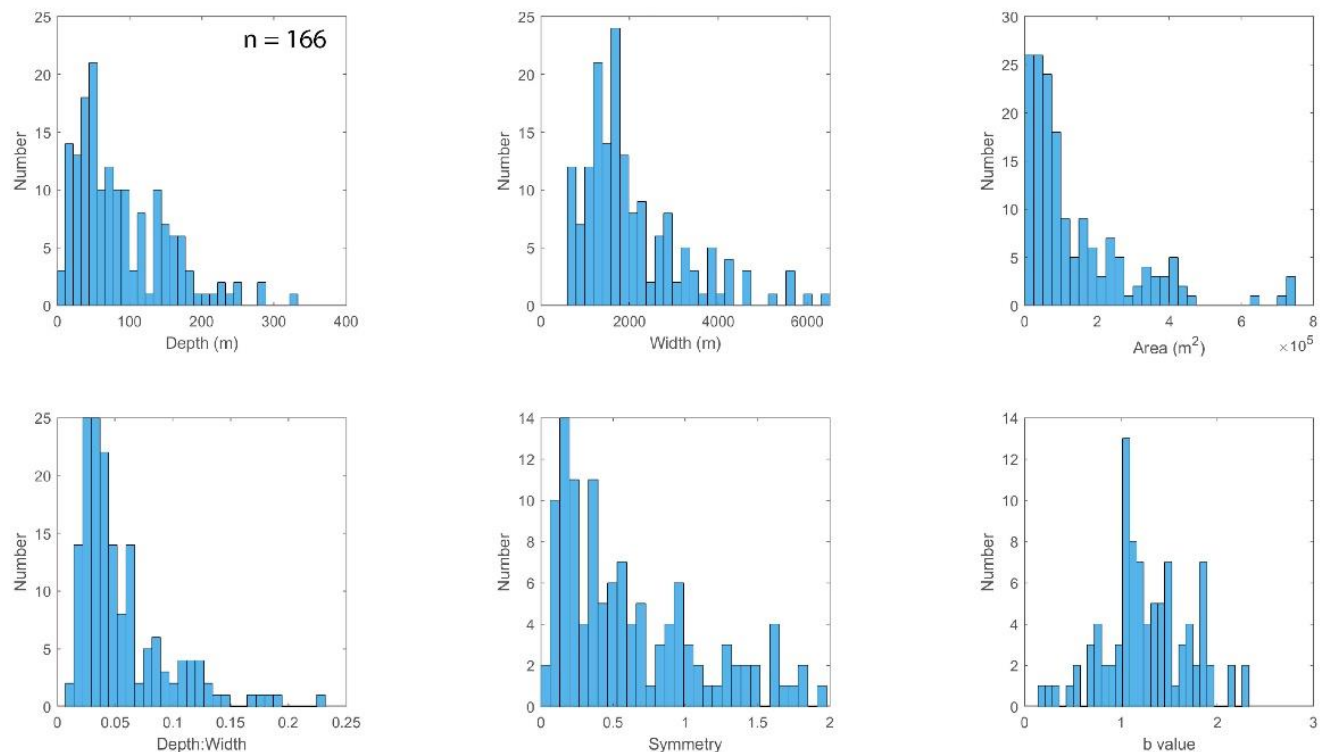

(b) Thwaites area bedrock channels
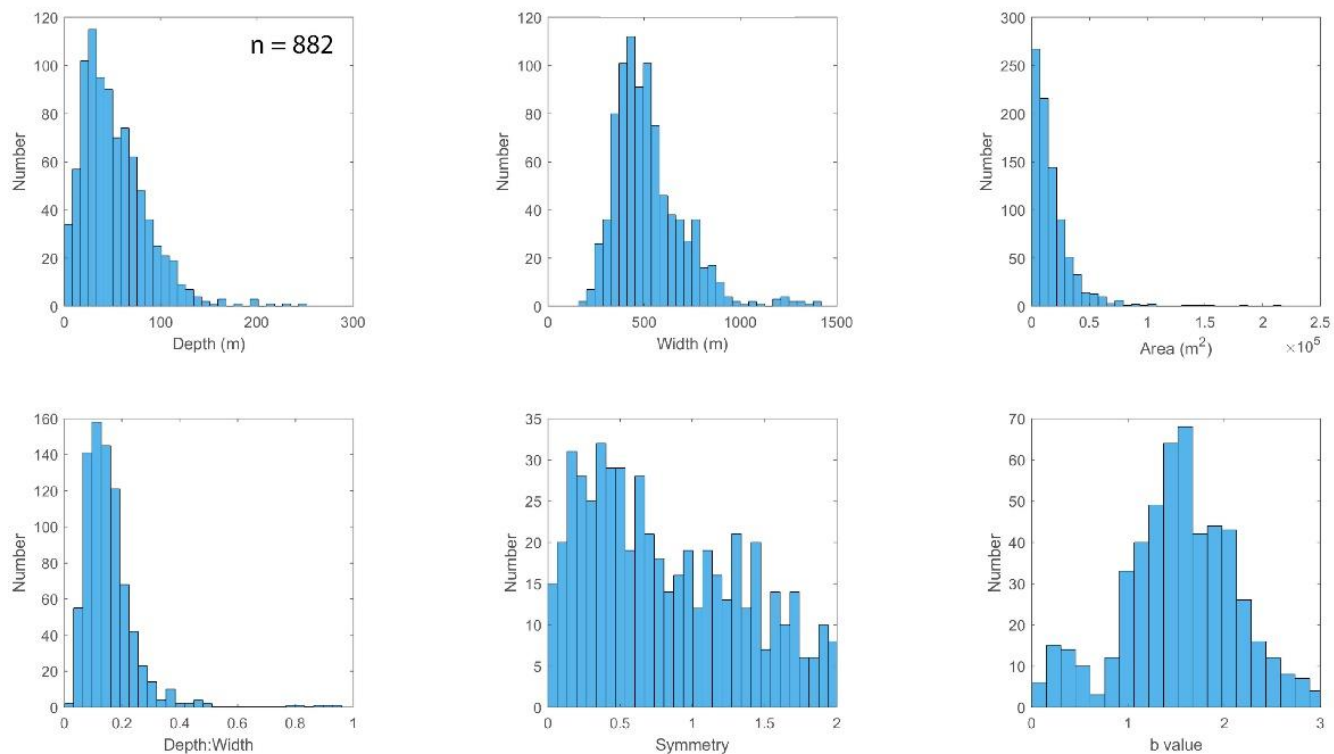

Supplementary Figure S3: Cross-sectional metrics for (a) bathymetric troughs and (b) bedrock channels identified from the MBES dataset in front of Thwaites Glacier (troughs and channels are mapped in Fig. 3). Note the different scales on some axes. Symmetry values of 1 denote perfectly symmetrical cross sections whilst values $>1$ and $<1$ denote left-skewed and right-skewed cross sections respectively. The b value assesses how $V$ - or $U$-shaped a cross section is; values of 1 are perfectly $V$ shaped, values of 2 are perfectly $\mathrm{U}$ shaped. b values greater than 2 reflect box shaped geometries and values below 1 indicate convex-upward forms. 
(a)

Thwaites MBES (1)

(along-flow)
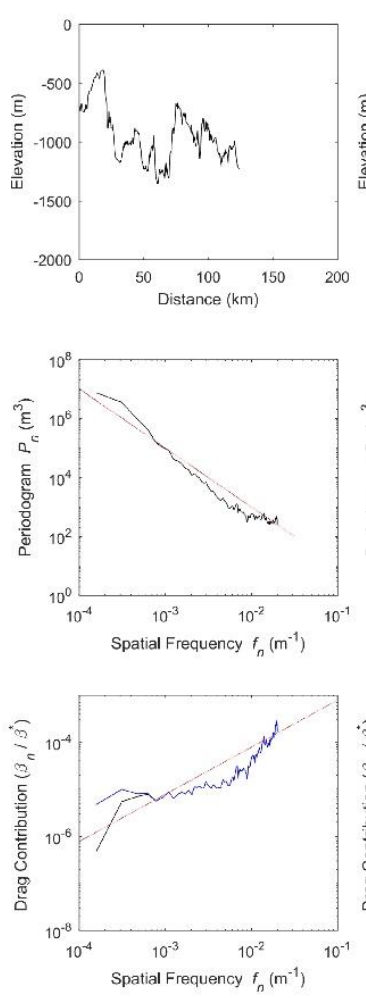

(b)

Thwaites MBES (2) (along-flow)
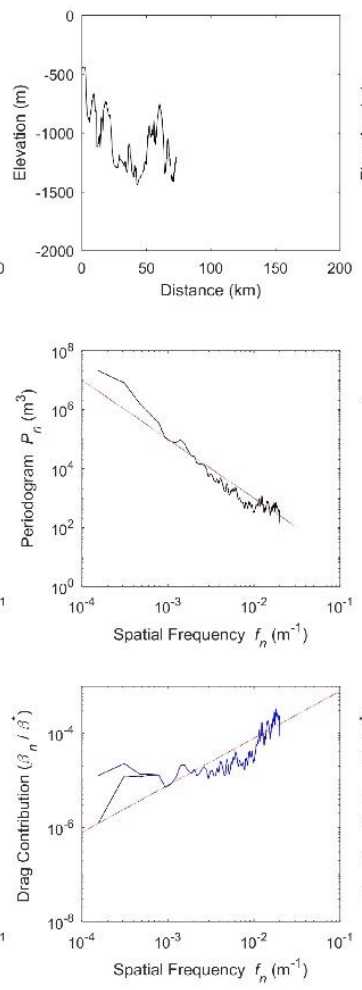

(c)

Thwaites MBES (3)

(along-flow)
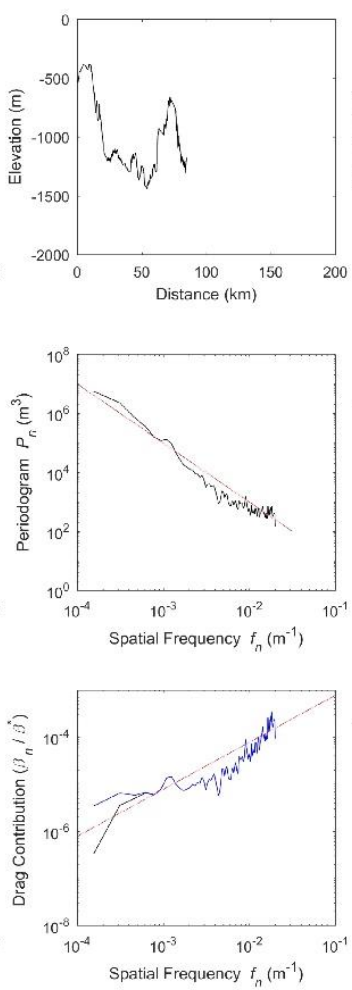

(d)

Thwaites MBES (4) (along-flow)
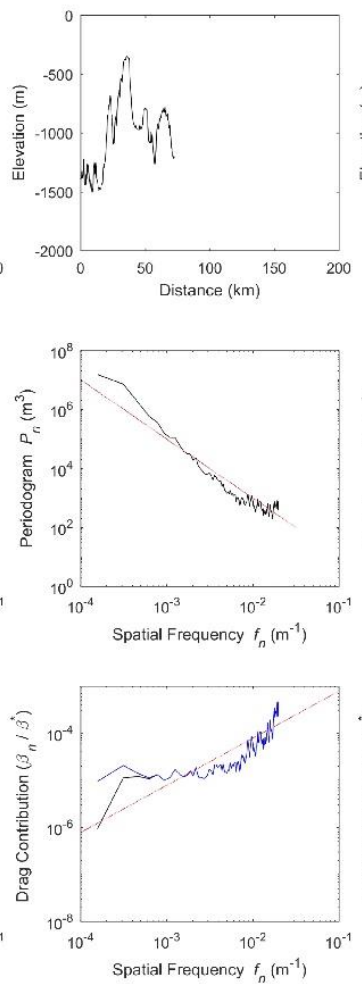

(e)

Thwaites MBES (5)

(along-flow)
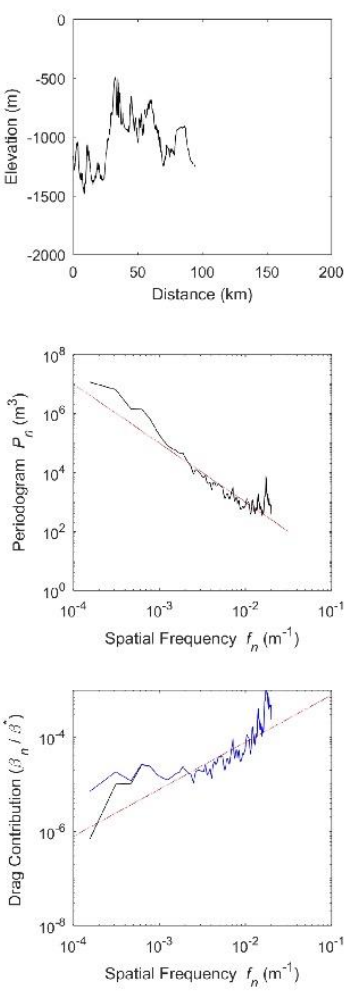

Supplementary Figure S4: Bed profiles (top), derived power spectra (middle) and basal drag contributions (bottom) for all bed profiles used in this study, for locations see Figs. SF1 and SF2: (a) Thwaites MBES along-flow profile 1; (b) Thwaites MBES alongflow profile 2; (c) Thwaites MBES along-flow profile 3; (d) Thwaites MBES along-flow profile 4; (e) Thwaites MBES along-flow profile 5. As per the main text (Section 4, Figs, 6, 7), the red line in power spectra and drag contribution plots are based on an assumption of Brownian motion (i.e. power decays as inverse square of spatial frequency). At low spatial frequency, drag contributions depend on the function $F$. Two limiting cases are shown: $F_{1}$ (blue), $F_{2}$ (black). 
(f)

Thwaites-PIB MBES

(6) (along-flow)
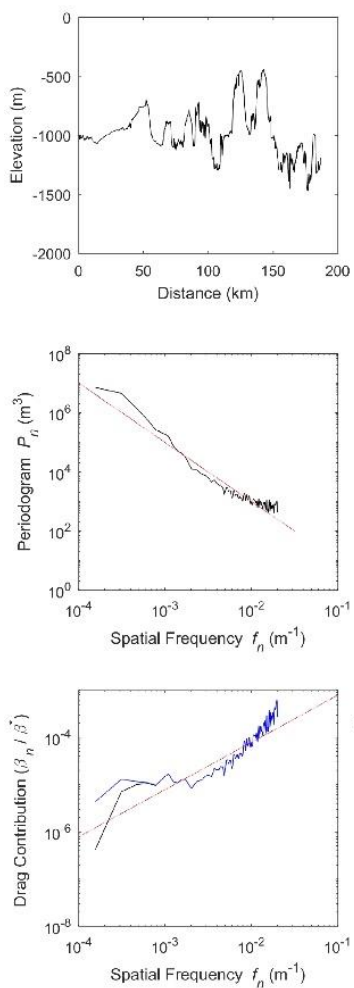

(g)

Thwaites radar (8) (along-flow)
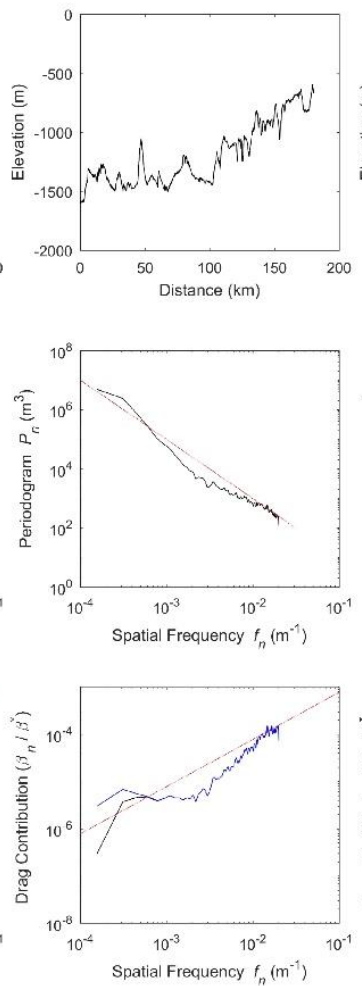

(h)

Thwaites radar (9) (along-flow)
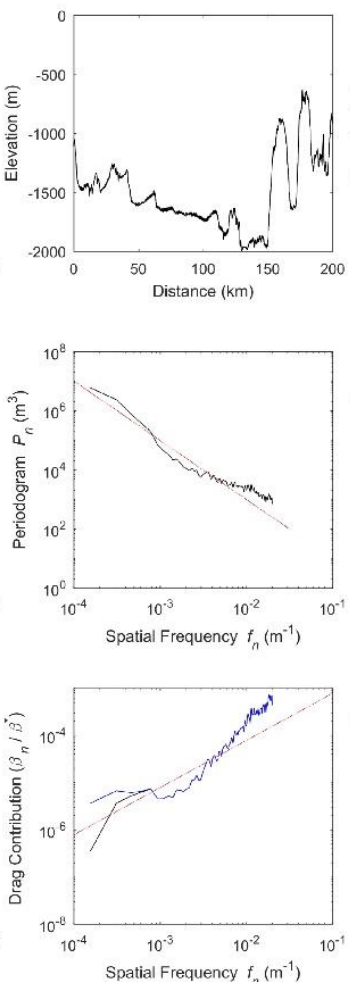

(i)

Pine Island radar (10) (along-flow)
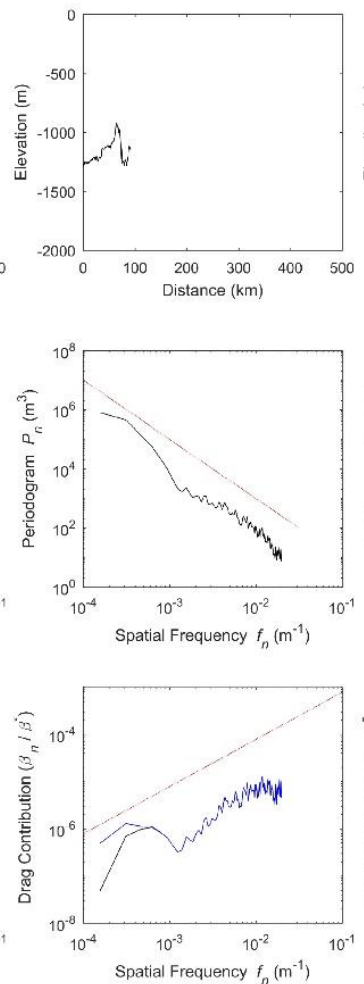
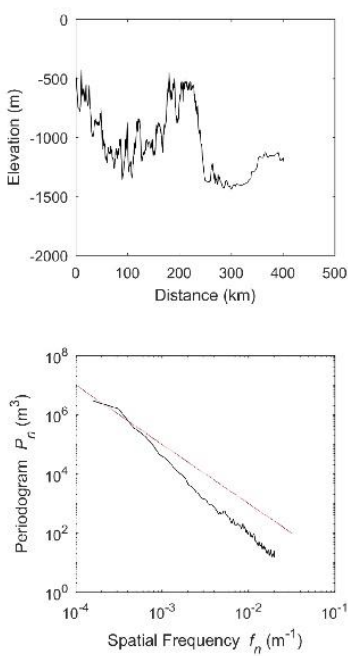

(j)

Pine Island radar

(11) (along-flow)

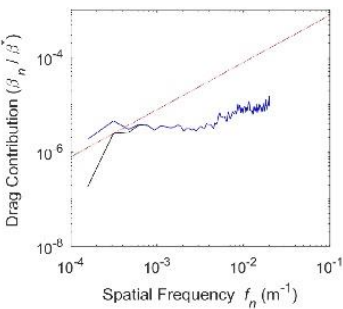

Supplementary Figure S4 (continued): Bed profiles (top), derived power spectra (middle) and basal drag contributions (bottom) for bed profiles used in this study, for locations see Figs. SF1 and SF2: (f) Thwaites-Pine Island MBES along-flow profile 6; (g) Thwaites radar along-flow profile 8 (upstream area); (h) Thwaites radar along-flow profile 9 (downstream area); (i) Pine Island radar alongflow profile 10 (upstream area); (j) Pine Island radar along-flow profile 11 (downstream area). 
(k)

Thwaites MBES

(a) (across-flow)
(I)

Thwaites MBES

(b) (across-flow) (m)

Thwaites MBES

(c) (across-flow) (n)

Thwaites MBES

(d) (across-flow) (o)

Thwaites MBES

(e) (across-flow) (p)

Dotson-Getz Tr.

(7) (along-flow) (q)

Dotson-Getz Tr

(f) (across-flow
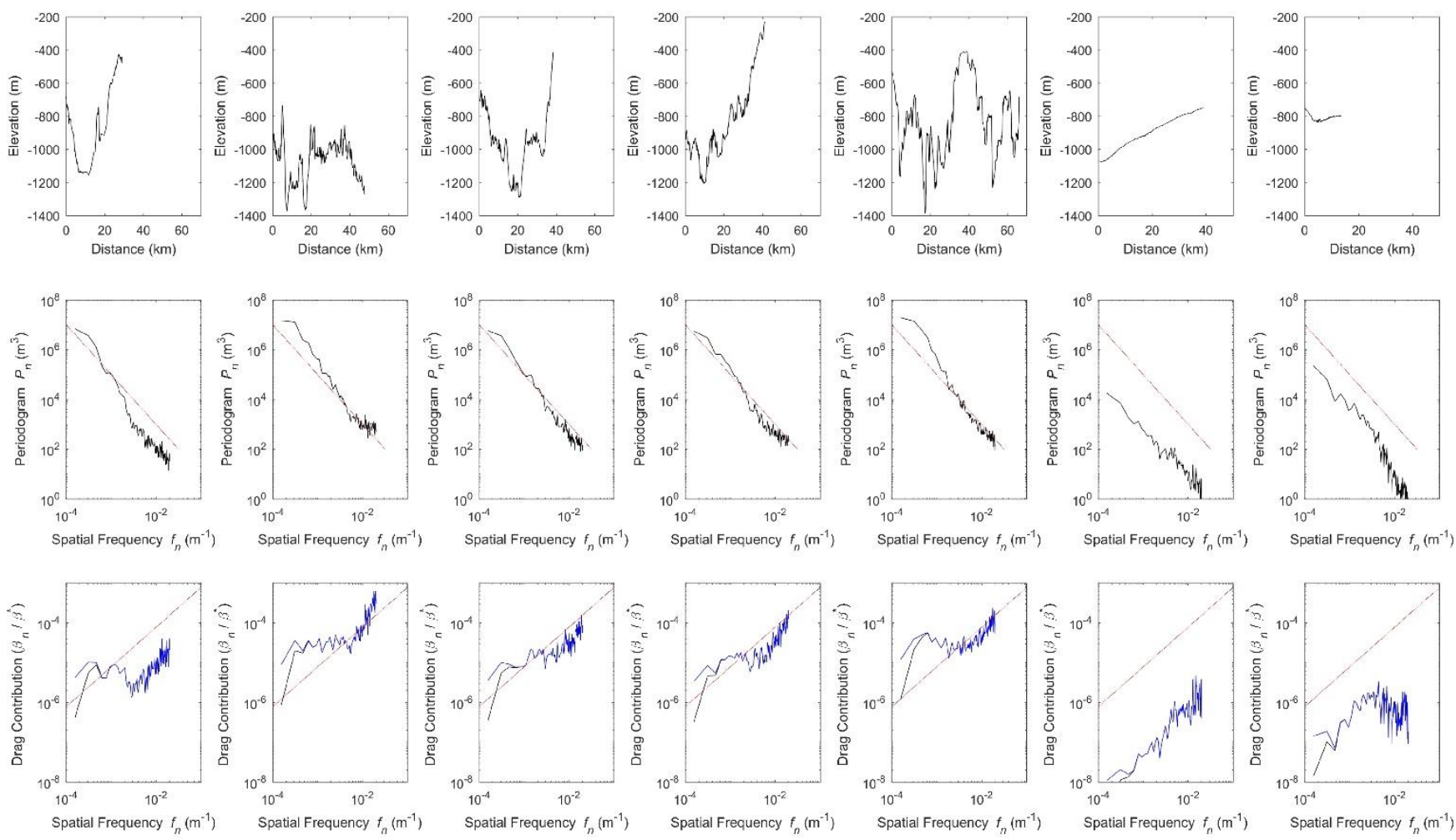

Supplementary Figure S4 (continued): Bed profiles (top), derived power spectra (middle) and basal drag contributions (bottom) for bed profiles used in this study, for locations see Figs. SF1 and SF2: (k) to (o) are Thwaites MBES across-flow profiles a-e, respectively; (p) is the Dotson-Getz Trough along-flow profile (7); (q) Dotson-Getz Trough across-flow profile f. 
(a)

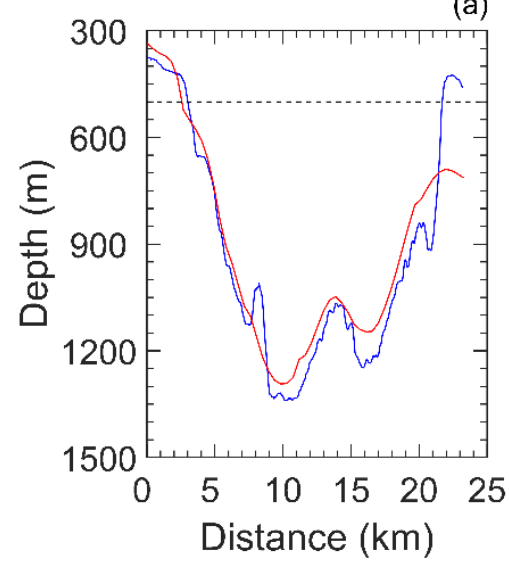

(b)

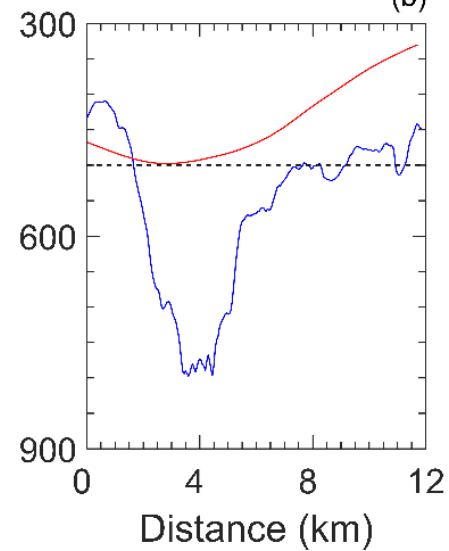

(c)

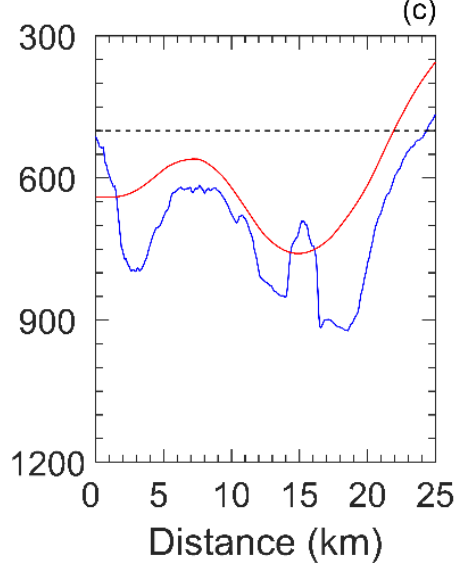

Bathymetry - Gravity inversion

Supplementary Figure S5: Comparisons of cross-sections over troughs that act as pathways for CDW to the Thwaites grounding zone from our MBES data (blue) and Millan et al. (2017) (red). Locations of the troughs are marked by asterisks in Fig. 8a. For trough T4 east of the EIS (a) the gravity-inversion only gives a 9\% error in the trough cross-sectional area compared with the MBES grid below $500 \mathrm{~m}$ (dashed line). Trough $\mathrm{T} 2$ between the $\mathrm{H1}$ and $\mathrm{H} 2$ highs (b) is not resolved by Millan et al. (2017), i.e. the error is $100 \%$ below $500 \mathrm{~m}$. The rugged sea floor of trough $\mathrm{T3}(\mathrm{c})$ is poorly-resolved by the Millan et al. (2017) grid resulting in a 38\% error in cross-sectional area.

The table below gives the area of any parts of the cross section that are below $500 \mathrm{~m}$ depth.

\begin{tabular}{lllll}
\hline Trough & NBP1902 area $\left(\mathrm{km}^{2}\right)$ & Millan area $\left(\mathrm{km}^{2}\right)$ & Area difference $(\%)$ & 'Missing water' $\left(\mathrm{km}^{2}\right)$ \\
\hline T4 & 10.3 & 9.78 & 4.72 & 0.52 \\
T2 & 0.88 & 0 & 100 & 0.88 \\
T3 & 5.17 & 3.20 & 38.1 & 1.97 \\
\hline
\end{tabular}

Supplementary Table 1: Cross-sectional area difference calculations for Millan et al. (2017) and the MBES grid for three troughs (locations are given as asterisks in Fig. 8a). Trough cross-sectional areas are calculated using trapezoidal numerical integration for any part of the trough below $500 \mathrm{~m}$; the depth below which CDW is assumed to be present. 
(a) Sub-bottom profile over $\mathrm{H} 2$ high (smooth return: sedimentary composition)

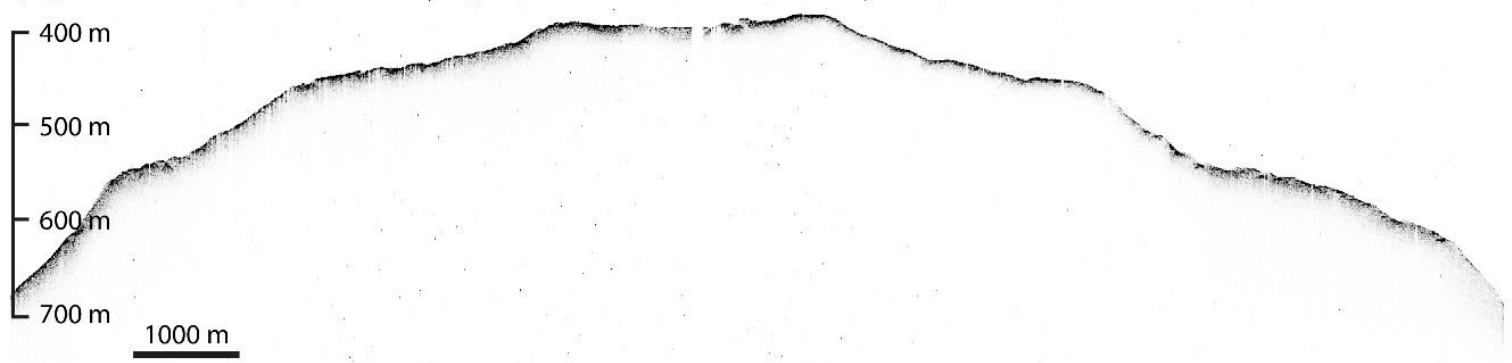

(b) Sub-bottom profile over $\mathrm{H} 1$ high (parabolic/rugged returns: hard bedrock)

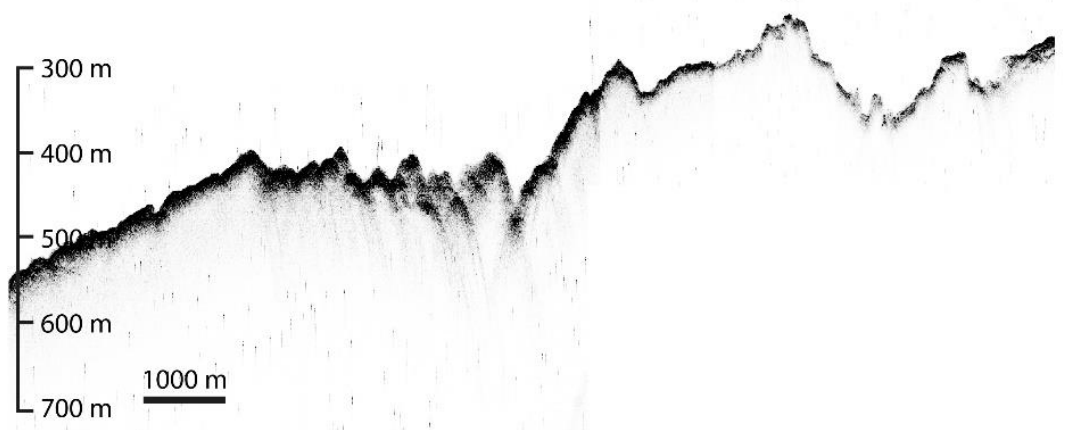

(c) Sub-bottom profile over $\mathrm{H} 3$ high (sub-bottom returns: unconsolidated sediment cover)

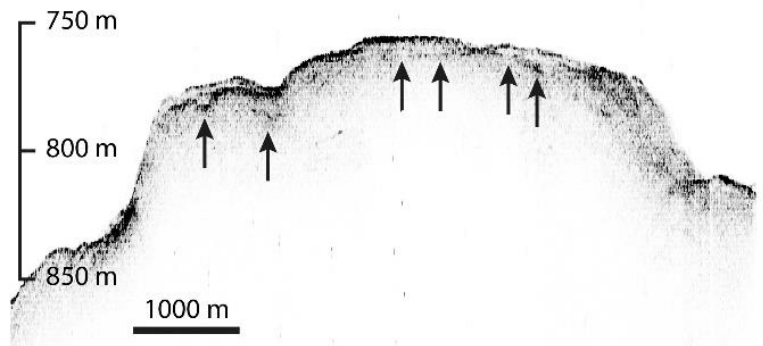

Figure S6: Example of Knudsen Chirp sub-bottom profiles over the sea-floor highs north of Thwaites Ice Shelf. (a) is a profile over the $\mathrm{H} 2$ high showing a very smooth return interpreted as sediment cover that is co-located sedimentary landforms (GZW) observed on MBES data. (b) is a profile from the flank of the $\mathrm{H1}$ high showing diffraction parabola from point reflectors at the sea floor interpreted as hard bedrock lithology. (c) is a profile from the $\mathrm{H3}$ high showing up to $15 \mathrm{~m}$ of unconsolidated sediment cover; subsea-floor reflections are marked by arrows. All profiles were acquired during cruise NBP19-02 (Larter et al., 2020). 